\title{
Patterns of death among migrant domestic workers in Jordan: retrospective analysis of 63 cases in a tertiary hospital
}

\author{
Hasan A. Abder-Rahman ${ }^{1 \dagger}$, Majd Al-Soleiti ${ }^{2^{*}} \mathbb{D}$, Ibrahim H. Habash ${ }^{1}$, Imad M. Al-Abdallat ${ }^{1}$ and Laith I. Al-Abdallat ${ }^{2}$
}

\begin{abstract}
Background: This article examines the patterns of death in migrant domestic workers (MDWs) in Jordan. Abuse and difficult circumstances may lead to attempts to escape, neglect, or suicide, but the current literature on death in this population is limited. We systematically explored all medico-legal cases of MDW deaths referred between 2006 and 2016 to the forensic department of one of the main tertiary medical centers in Jordan.

Results: Sixty-three recorded cases of MDWs death were found. Forty-seven (74.6\%) died due to unnatural causes, 15 (23.8\%) died naturally, and 1 (1.6\%) was undetermined. The rate of suspected suicide comprised 58.3\% of unnatural deaths. The most common methods of suicide were hanging and falling from a height.

Conclusions: This study shows high rates of unnatural death among MDWs in Jordan, many of which with suspicious circumstances. It also indicates that natural deaths are largely attributed to preventable causes. Future studies should include other referral sites (hospitals and forensics departments), to better address the complexity and magnitude of this population's death circumstances, gain a comprehensive understanding of their issues, and work toward finding a solution. We recommend that special attention is given to MDWs in Jordan and the region to protect their rights on all levels.
\end{abstract}

Keywords: Migrant, Domestic workers, Cause of death

\section{Background}

Migrant domestic workers (MDWs) comprise a large group of foreign workers in Jordan. According to the annual report released by the Ministry of Labor in 2016, there are over sixty-two thousand domestic workers in Jordan, in addition to thousands of irregular workers (Jordan Ministry of Labor 2016). The countries of origin of migrant workers (ranked by the numbers) include Bangladesh, Philippines, Sri Lanka, India, Pakistan, and Indonesia (Jordan Ministry of Labor 2016).

Worldwide, there are at least 67 million domestic workers according to International Labor Organization

\footnotetext{
* Correspondence: majdsoliti@gmail.com

${ }^{+}$Hasan A. Abder-Rahman and Majd Al-Soleiti are co-first authors.

${ }^{2}$ School of Medicine, University of Jordan, Queen Rania St, Amman 11942, Jordan

Full list of author information is available at the end of the article
}

(ILO), $80 \%$ of them are women and about $17 \%$ of them are migrant domestic workers (International Labor Organization 2019a, b). In the majority of cases, they come from disadvantaged environments and have been highlighted in the literature as a population vulnerable to exploitation and abuse all over the world (International Labor Organization 2019a, b). This vulnerability is worsened in the case of female migrants specifically, as anti-immigration social practices change the way workers perceive violence, access to services and the subsequent response (Erez et al. 2009). They are also usually exposed to high levels of stress and social isolation, even with good physical health (Anjara et al. 2017; International Labor Organization 2013).

According to the ILO, migrant domestic workers are disproportionately exposed to abuse compared to nationals due to different reasons, such as their 
dependence on recruitment agencies, limited freedom and access to justice, and confiscating personal documents by employers (International Labor Organization 2019a, b). The ILO Convention No. 189 and Recommendation No. 201 were adopted in 2011, which were mainly designed to protect MDWs rights, such as having a written contract to support them legally. Although these are considered historic improvements, the recommendations still need better follow-up to ensure that correct implementation by the authorities (International Labor Organization 2019a, b; Human Rights Watch 2008a, b).

There has been a rise of MDWs in Jordan and the region due to the growth of the oil industry in the Arabian Gulf and the rising standards of living for citizens of Middle Eastern countries. Jordan has been one of the main countries to recruit these workers thereby creating different opportunities for migrants, especially those from Southeast Asia (Manseau 2006).

The life conditions, health issues, and abuse of workers from these countries has become a phenomenon that has been studied recently by researchers from their home countries (Wickramage et al. 2017; Simkhada et al. 2018) and other researchers from their countries of employment (Fernandez 2018; Sonmez et al. 2011; Kronfol et al. 2014). These issues have been also reported frequently by the ILO and the Human Rights Watch (HRW) (International Labor Organization 2018a, b; Human Rights Watch 2008a, b). These studies and reports found that MDWs are suffering from poor living and working conditions making them more vulnerable to neglect, abuse and physical and mental health problems.

In Jordan, the National Center for Human Rights found that employers regularly violate MDWs basic human rights despite active changes in regulations and laws regarding employers and recruitment agencies by the Jordanian government (Jordan Ministry of Labor $2009,2015)$. These violations include, but are not limited to, confiscating their passports and residency permits, delayed payment of wages, lack of legal protection, and unsafe life conditions, such as working for long hours and depriving them of vacation days and sick leave (Jordan National Center for Human Rights 2015). Such circumstances play a primary role in worsening MDWs physical and mental health, whereby they experience difficult working conditions compounding their existing problems.

A recent study in Jordan described the consequences of different forms of abuse ultimately leading to attempts to escape or suicide (Tamkeen Fields for Aid 2015). However, while some literature examined the physical and emotional abuse MDWs deal with on a daily basis, there have been no detailed studies on the patterns and circumstances of death in this population.
Human rights organizations and the media have addressed the subject of MDW abuse and suicide. However, there is a significant lack of accurate data, statistics, and scientific research, while much of the current data remains as speculation. Although referral cases of deceased MDW is a regular occurrence in Jordan, there is no evidence that previous research had been conducted on this issue before.

In this study, we systematically explored all cases of death in MDWs, which were referred to the forensic department between 2006 and 2016 to one of the main tertiary referral medical centers in Jordan. Our aim is to assess the patterns, causes, and manners of death in MDWs, while examining their relationship with different demographic factors and other variables.

\section{Methods}

\section{Setting}

The study was conducted at a tertiary center, which is considered one of the main tertiary medical centers in Jordan. The forensic department of the hospital covers a wide area, from which it receives the forensic cases. The area is known for having a large proportion of migrant domestic workers.

\section{Design}

We used a descriptive retrospective study design, reviewing all cases of death in MDWs referred to the forensic department in the years between 2006 and 2016. The data was collected from the department's records. All cases were classified according to: date, age (child-bearing age or not), nationality, cause of death, manner of death (natural or unnatural and their sub-types), and presence of old injures/toxins/sexual abuse.

\section{Inclusion criteria}

The inclusion criteria comprised of non-Jordanian females who work in a paid-job as domestic workers. Domestic work is defined as "work performed in or for a household or households" according to the ILO (International Labor Organization 2011). We chose to study MDW cases due to the significant increase of recent medico-legal referrals from this population. Another reason was the media's and human rights organizations' coverage of their current life conditions, abuse, and death. The recorded cases of MDW death in our center comprise only females, thereby explaining the reason behind the exclusion of males in our study.

All cases in this study were medico-legal, needing to fulfill at least one of these criteria: unnatural death, or natural death that has any of the following features: sudden and/or unexplained and/or unexpected and/or suspicious. 


\section{Forensic classification and coding}

All referred cases are examined and the cause of death $(\mathrm{CoD})$ is determined by the examining doctors (Forensic Pathologists). Cases are also classified legally according to the manner of death (MoD) into: "natural" (death due to disease), "unnatural" (homicide, suicide, or accident) and "undetermined"; the specific unnatural MoD may not always be determined by medical examiners and may require further police investigation and intervention.

\section{Data analyses}

Descriptive statistics were used. The prevalence of natural and unnatural deaths was calculated. Then, a further classification and prevalence measurement was done to the sub-types of unnatural death. The data was entered and analyzed using SPSS for Windows (Version 20.0).

\section{Ethical approval}

The research was approved by the Institutional Review Board (IRB) of The University of Jordan.

\section{Results}

This study examined a total of 63 victims (mean age $=$ 29.3 years). Of the total 63 cases, 25 (39.7\%) were from Indonesia, 17 (27.0\%) from Bangladesh, 10 (15.9\%) from Sri Lanka, 8 (12.7\%) from Philippines, and 1 (1.6\%) from Kenya while 2 (3.1\%) were unrecorded. All cases except one were in the child-bearing age, with the majority (58.7\%) between 20 and 29 years old $(n=37)$, and only 2 cases in the extremities of age $(1<20$ years old, and 1 $>50$ years old). Twenty (31.7\%) of the cases were between 30 and 39 years, and 3 (4.7\%) were in the 40-49 years age group.

At least 3 cases of unnatural death were recorded in our department annually. The year with the largest number of cases, regardless of the cause, was
2008 (9 cases). Forty-seven (74.6\%) cases died from unnatural causes, 15 (23.8\%) from natural causes and 1 (1.6\%) from an undetermined cause. Table 1 describes the distribution of cases across years from 2006 to 2016.

Natural causes of death included: Dehydration from gastroenteritis, acute coronary syndrome, ruptured peptic ulcer, pneumonia, tuberculosis, appendicitis followed by rupture and peritonitis, brain hemorrhage, complications of liver failure, kidney failure, leukemia, valvular heart diseases, and complications of severe thyroid hypertrophy. Unnatural deaths were further divided to: confirmed homicide, confirmed accidental death, confirmed suicide, and suspected suicide (the last category was with legal determination of suicide that is uncorroborated by medical opinion or evidence). The majority of unnatural death cases were suspected suicide unconfirmed by forensics $(59.6 \%, n=28)$. The rest comprised of 9 cases (19.2\%) of confirmed suicide, $5(10.6 \%)$ cases of confirmed homicide, and 5 (10.6\%) cases of confirmed accidental death.

In Table 2, unnatural deaths' four subcategories were further detailed to show the exact circumstances of death:

- Nine out of forty-seven (19.2\%) cases of confirmed suicide as determined by the medical examiners and detectives. All cases of suicide were due to death by hanging.

- Five out of forty-seven (10.6\%) cases of confirmed accidental death as determined by the medical examiners and detectives. Carbon monoxide $(\mathrm{CO})$ poisoning is attributed as the cause of death in four cases, while a road traffic accident (RTA) was determined to be the cause of death in one.

- Five out of forty-seven (10.6\%) cases of confirmed homicide as determined by the medical examiners and detectives. Strangulation was determined to be

Table 1 Cases of death in MDWs according to year

\begin{tabular}{lll}
\hline Year & Total number of death cases & Number of unnatural death cases \\
\hline 2006 & 5 & 3 \\
2007 & 3 & 3 \\
2008 & 9 & 5 \\
2009 & 5 & 3 \\
2010 & 7 & 6 \\
2011 & 6 & 5 \\
2012 & 7 & 5 \\
2013 & 4 & 3 \\
2014 & 7 & 5 \\
2015 & 6 & 5 \\
2016 & 4 & 4 \\
\hline
\end{tabular}


Table 2 Profile of unnatural deaths and their circumstances among the domestic workers

\begin{tabular}{lll}
\hline Manner of death & Specific CoD & Number of cases \\
\hline Confirmed suicide & Hanging & 9 \\
Confirmed accidental death & CO poisoning & 4 \\
& RTA & 1 \\
Confirmed homicide & Strangulation & 3 \\
Suspected suicide unconfirmed by medical examiners & Blunt trauma & 2 \\
& Poisoning & 1 \\
& Falling from a height & 25 \\
\hline
\end{tabular}

the cause of death in three cases and inflicted blunt force trauma (beating) in two cases.

- Twenty-eight out of forty-seven (60.4\%) cases of suspected suicide as determined by detectives, with no evidence or confirmation by the medical examiners. The cause of death was attributed to: drug overdose in $1 / 28(3.5 \%)$, severe thermal burns in $1 / 28$ (3.5\%), and severe chemical burns after caustic material ingestion in $1 / 28$ (3.5\%). However, the majority of cases of suspected suicide $25 / 28$ (89.2\%) were attributed to falling from a height; the latter comprises $39.6 \%$ of all cases in this study.

There was evidence for sexual abuse in four cases (6.3\%). Two of the cases exhibited signs of rape (which is defined in Jordan as sexual intercourse with a nonwife female without her consent), with evidence of enlarged anal openings and recent hymen defloration. Another case was found to have semen stains on the suprapubic area with an enlarged uterus and a dead fetus. The fourth case was found to be pregnant in her second trimester.

\section{Discussion}

This study represents one of the first attempts to examine death patterns among female MDWs in Jordan by analyzing case records over the last decade in a main referral tertiary medical center in the country, which covers a wide area known to harbor a lot of the MDWs in Jordan. These records may be used as a representative sample, and we estimate that results can be generalized with caution for all of Jordan.

\section{Unnatural death rates}

The results of this study demonstrate alarming rates of unnatural death $(74.6 \%)$ relative to natural deaths $(23.8 \%)$ and undetermined causes (1.6\%). According to the available mortality data on the general population from Jordan Ministry of Health, the average rate of external (unnatural) causes of mortality is $9.52 \%$ among all causes of death over the years 2006-2015 (Jordan
Ministry of Health 2006-2015). Our sample's rate of unnatural death is significantly higher $(74.6 \%)$. This indicates that this population is highly more vulnerable to unnatural death, compared to the general population.

The literature does not contain any similar studies for comparison, but we estimate that this is similar to the rates in the country and the region. In Lebanon for example, a 2008 Human Rights Watch report stated that 1 domestic worker dies every week with most cases classified as suicide (Human Rights Watch 2008a, b). Unfortunately, there are no sufficient and accurate statistics about number of deaths (natural and unnatural) in MDWs in Jordan or in the region, so we cannot compare the rates of death in our sample with the rates of death in the general MDWs population.

Using another approach to validate our results, we examined our own records. The total number of female medico-legal cases that were referred to our department over the years from 2006 to 2016 was 1618 cases from the general population. Excluding natural causes and road traffic accidents; the number was reduced to 260 cases, including our 46 cases of MDWs unnatural deaths ( 1 case of RTA was excluded). The unnatural death in MDWs comprised 18\% (46/260) of these cases. Our hospital receives cases from a district with a total population of 803,440 thousand (Jordan Department of Statistics 2018). The geographic distribution of the MDW population in Jordan is unavailable. Comparing the total number of MDWs in Jordan (approximately $62,000)$ with the population of the district yields an approximation of $8 \%$ of the district's population. Thus, MDWs deaths comprise $18 \%$ of these cases while representing only $8 \%$ of the district's population. These numbers are alarming, especially since they may be underestimated with many cases referred to other centers and workers being geographically distributed to other areas.

Comparatively, most of the 1618 examined medicolegal cases were found to be dead due to natural causes $(n=1248)$. However, in this sample of medico-legal cases of MDWs, unnatural causes were present in the 
vast majority of cases $(74.6 \%, n=47$ out of 63$)$, while natural causes comprised only $23.8 \%$ ( $n=15$ out of 63 ) of the cases. This means that this population is more vulnerable to unnatural death, compared to the general population that we examined. Our results are expected, given that this population is known to be particularly vulnerable to the full spectrum of abuse: physical, financial, verbal, emotional abuse, and neglect (Tamkeen Fields for Aid 2015).

\section{Suspicious deaths and the issue of suicide}

There were different elements of suspicion in our study sample; including age; where nearly all MDWs are young and in child-bearing age, gender; where women are more vulnerable to abuse, prior injures, sexual abuse, and that different cases had prior attempts to escape that ended in failure.

The rates of suspected suicide deaths are very high among unnatural deaths (58.3\%) and among total cases (44.4\%). While the medical examiners were not able to determine the manner of death in these cases, the detectives suspected suicide as the manner, and subsequently determined them as suicides. Careful police investigation of conditions and circumstances is essential and warranted, although it may not be properly implemented in real life situations.

Falling from a height comprised a high percentage of these suspicious deaths: $52 \%$ of unnatural deaths and $39.7 \%$ of total deaths. These deaths may be due to suicide, homicide, accidental death (which may be due to failed attempt to escape). In one of the cases of suspicious death, one victim tied her clothes together in order to escape from the window but shortly afterwards fell from a height due to the unraveling of her makeshift escape mechanism. This case was reported as a suicide, while further investigation may have yielded different outcomes, such as homicide or accidental death.

On the other hand, investigating and correctly identifying the factors that led to these results, regardless of the cause and manner of death, is imperative. Suicide is an act that requires careful studying and understanding in order to be prevented. For example, in three cases of death due to falling from a height, evidence of previous attempts at committing suicide and self-harm were identified during the postmortem examination where victims exhibited signs of healed horizontal scars suggestive of previous self-harm. Despite that, these cases were closed after being ruled a suicide without utilizing any effort or resources in identifying the core problem or factors that may have led to this kind of behavior. Better surveillance programs designed according to international standards (United Nations Human Rights 1990) would have played a role in changing the circumstances and consequences.

Confirmed and suspected suicide cases comprised the majority of unnatural deaths (77.0\%) and all cases (58.7\%). This is consistent with the findings of the Human Rights Watch in Lebanon (Human Rights Watch 2008a, b).

\section{Consistency of the phenomenon}

We found that an estimated 3 cases of unnatural death and 6 cases of death on average were examined each year. This shows that the phenomenon is prevalent and not a temporary issue. Furthermore, we estimate that the situation may be getting worse with a projected increase of abuse and consequently death. The recent travel ban to Jordan imposed by the Indonesian and Philippine governments on their citizens may indicate the rising severity of the situation and the need to limit any further abuse or death (BBC news 2008; The Jordan Times 2015).

\section{Natural death due to neglect}

This study shows that most causes of death, including natural causes, in MDWs in Jordan may be preventable. The natural death cases included appendicitis, dehydration, pneumonia and thyroid hypertrophy, where each may have been prevented given proper care and treatment. This may indicate the degree of neglect and maltreatment MDWs suffer from on a daily basis. It shows similar results to research suggesting that the population is suffering from clear health disparities and neglect in terms of regular healthcare in different countries of the region (Fernandez 2018; Sonmez et al. 2011; Kronfol et al. 2014; Tamkeen Fields for Aid 2015).

\section{Root causes (the context in Jordan and the region)}

The conditions of MDWs in the Middle East Arab countries have been given more attention and thorough investigations in recent years. The ILO published many reports targeting the Arab states. Reports from Jordan, Lebanon, and Kuwait in particular showed the critical role of recruiting agencies and employers' perspectives and attitudes. They also concluded that it is necessary to put labor regulations in this sector and protect MDWs through institutional policies (International Labor Organization 2015a, b, 2016). A key report was published in 2018 and showed that important progress has been made over years by some countries in the Middle East in terms of policies, but implementation and enforcement remain major challenges (International Labor Organization 2018a, b).

Comparatively, several Human Rights Watch reports have highlighted the poor conditions of MDWs in different Arab countries and emphasized the dangers of the 
exploitative "Kafala" sponsorship system (that is implemented in most countries), lack of sufficient protective policies and extreme inhumane behaviors toward MDWs (Human Rights Watch 2008b, 2017). "Kafala" system is the model used in most countries in the region to regulate the process of recruiting MDWs, through which the employer "guarantees" the worker, meaning that they assume economic and legal responsibility of them. This system was criticized for many reasons, most importantly for contributing to abuse and exploitation by giving restrictive power to the employers and private agencies in the recruitment and regulation process (Varia 2011; Damir-Geilsdorf and Pelican 2018).

Few reports have been released examining MDW treatment and living conditions in Jordan; however, there are some that explore the social contexts of MDWs. One of the key studies named "Invisible Women" by "Tamkeen", a non-governmental organization (NGO) in Jordan, highlighted a number of factors: gender, where a vast majority if not all are women; significant cultural differences whereby many MDWs do not speak or understand Arabic; irregular status (tens of thousands of them); and nature of required work where many MDWs are expected to perform duties beyond the job description, such as taking care of children. These factors exacerbate their isolation and feelings of alienation that are already present in the post-migration period (Tamkeen Fields for Aid 2015). Moreover, according to The National Center for Human Rights, workers in Jordan have no way to complain or protect their own personal rights. Most of them do not have health insurance despite the fact that their employers are required by law to provide it (Jordan Ministry of Labor 2009; Jordan National Center for Human Rights 2015).

An article that explored the dynamic relationships between Sri Lankan domestic workers in Jordan and the employing families argued that an essential strategy used by both groups involves the construction of relations of dependency. It may be that any disturbance in the balance of this relationship leads to negative results, such as abuse, attempts to escape, and death (Frantz 2008).

\section{Families left behind}

The death of MDWs in a foreign country affects their families and friends in their home countries. Following the determination of the cause of death and the medical examiners' report, these documents are translated to English and the migrant worker's embassy communicates with their family to process the next steps. These workers usually come from less fortunate backgrounds with many dependents, including parents and particularly children, left behind who suffer from their absence financially and emotionally (Tamkeen Fields for Aid 2015; Siriwardhana et al. 2015; Asis 2006).

The consequences may be so severe as to affect the MDW families who were shown to suffer from a lack of proper mechanisms to help them deal with fears and concerns about negative events such as injury, abuse or a family member's death (Siriwardhana et al. 2015). Post-migration periods can be stressful and affect the well-being of these families, and death can be the unfortunate extreme negative end result of the worker's and their family's experience.

We think that a sufficient amount of regular communication between the workers and their families can significantly help both parts cope better and have healthier lives. This can be further implemented with proper awareness campaigns and training for the MDW prior or shortly after arriving in their countries of employment, as well as by clear guidelines and policies in the employing countries.

\section{Conclusions}

This research shows that a significant number of migrant domestic workers in Jordan die from unnatural causes, while cases of death involving natural death were found to be easily preventable. Deaths in this population, regardless of the cause, are almost always suspicious. Elements of suspicion include age, nationality, old injures, sexual abuse, and circumstances of death. A thorough investigation and examination of the circumstances and events surrounding their death must be implemented prior to coming to a ruling.

\section{Recommendations and future directions}

Future studies can include more hospitals and forensic departments from all over Jordan and the region to widen the scope of work. They can also involve current workers to discuss their working conditions and needs on a deeper level. Providing accurate information which clarifies the extent and danger of this phenomenon will yield a new standard of MDW recruitment and followup for their basic rights and health maintenance.

Furthermore, we recommend that countries of origin, employing countries, and recruiting agencies design certain measures to ensure good selection and protection of the workers. They might also provide workshops and trainings for workers and for hosts before signing the final contract and starting their job. There is a need to follow-up with these workers after employment to ensure adequate living and working conditions, protect their rights and maintain good healthcare standards. Adequate implementation of law practices and different inspection visits are essential as they have proven to be effective in Jordan (Al-Natour 2016). 
Finally, the medico-legal system and its major parts should stand and revisit laws and protocols pertaining MDWs more often. The General Attorney and Forensic doctors should be more aware and careful when approaching these cases, and police investigations should be more thorough and examine the different factors that may have led to MDW injury and death. International human rights and anti-human trafficking organizations should also get more involved in this issue, as it affects different regions of the world.

\section{New contribution to the literature}

This paper is one of the first scientific studies on the patterns of death in migrant domestic workers in the Middle East. It is also the first to provide and analyze data of the cases referred over 11 years of experience to a forensic department in a hospital. Moreover, the study resulted in significant data and can be considered as groundwork for future studies in Jordan, the region and worldwide.

\section{Limitations}

This study has a few limitations. First, it only studies a specific set of cases which were referred to one hospital in Jordan, and thus its results can be generalized, albeit with caution. Secondly, this study describes the cases and possible causes but several aspects could not be determined due to the complexity of the issue. Thirdly, we only approached the issue with the confirmed death cases and our study does not include data from current MDWs which may have served to further corroborate our findings. Finally, access to official statistics on MDWs and local population is very limited; this may have constrained any potential comparisons between our results and other numbers, such as geographical distribution of MDWs in Jordan, causes of death when compared to the general population, and trends of MDW abuse and death compared to the surrounding countries and the region.

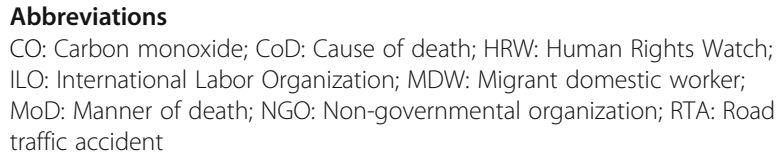

\section{Acknowledgements}

We thank the staff of the Forensic Medicine and Toxicology Department at the Jordan University Hospital for their help in conducting the study.

\footnotetext{
Authors' contributions

MA: designed the study, reviewed the files and collected data, conducted the statistical analysis, and drafted the manuscript. HA: designed the study, reviewed the files and collected data, conducted the statistical analysis, and drafted the manuscript. $\mathrm{H}$ : reviewed the files and collected data and drafted and reviewed the manuscript. IA: conceptualization and helped in drafting and reviewing the manuscript. LA: conceptualization and helped in drafting and reviewing the manuscript. The authors have read and approved the manuscript.
}

\section{Funding}

This research did not receive any specific grant from funding agencies in the public, commercial, or not-for-profit sectors.

\section{Availability of data and materials}

All the original data that was presented, mentioned, and analyzed in this research is available and accessible upon request in the medical forensic records and files at The University of Jordan hospital. The medico-legal reports are not publicly available due to their private/legal nature but may be provided upon request for scientific inquires or research.

\section{Declarations}

Ethics approval and consent to participate

The research was approved by the Institutional Review Board (IRB) of The University of Jordan. The number of IRB form approval is 1141/2021/67.

\section{Consent for publication \\ Not applicable.}

\section{Competing interests}

The authors declare that they have no competing interests.

\section{Author details}

${ }^{1}$ Pathology and Microbiology and Forensic Medicine Department, School of Medicine, University of Jordan, Amman, Jordan. ${ }^{2}$ School of Medicine,

University of Jordan, Queen Rania St, Amman 11942, Jordan.

Received: 10 June 2021 Accepted: 31 August 2021

Published online: 10 September 2021

\section{References}

Al-Natour E (2016). Domestic workers: souls suspended from windows. Retrieved from: https://www.7iber.com/society/domestic-workers-falling-cases/. Accessed 7 July 2021.

Anjara SG, Nellums LB, Bonetto C, Bortel TV (2017) Stress, health and quality of life of female migrant domestic workers in Singapore: a cross-sectional study. BMC Womens Health 17(1):98. https://doi.org/10.1186/s12905-017-0442-7

Asis MMB (2006) Living with migration. Asian Popul Stud 2(1):45-67. https://doi. org/10.1080/17441730600700556

BBC news (2008) Philippine ban for Jordan 'abuse'. Retrieved from: http://news. bbc.co.uk/2/hi/middle_east/7207094.stm. Accessed 7 July 2021.

Damir-Geilsdorf S, Pelican M (2018) Between regular and irregular employment: subverting the kafala system in the GCC countries. Migr Dev 8(2):155-175

Erez E, Adelman M, Gregory C (2009) Intersections of immigration and domestic violence: voices of battered immigrant women. Fem Criminol 4(1):32-56. https://doi.org/10.1177/1557085108325413

Fernandez B (2018) Health inequities faced by Ethiopian migrant domestic workers in Lebanon. Health Place 50:154-161. https://doi.org/10.1016/j.hea Ithplace.2018.01.008

Frantz E (2008) Of maids and madams. Crit Asian Stud 40(4):609-638. https://doi. org/10.1080/14672710802505323

Human Rights Watch (2008a) Lebanon: migrant domestic workers dying every week. Retrieved from: https://www.hrw.org/news/2008/08/26/lebanon-migra nt-domestic-workers-dying-every-week. Accessed 7 July 2021.

Human Rights Watch (2008b) As if I am not human. Retrieved from: https://www. hrw.org/report/2008/07/07/if-i-am-not-human/abuses-against-asian-domesticworkers-saudi-arabia\#. Accessed 7 July 2021.

Human Rights Watch (2017) Working like a robot. Retrieved from: https://www. hrw.org/report/2017/11/14/working-robot/abuse-tanzanian-domesticworkers-oman-and-united-arab-emirates\#. Accessed 7 July 2021.

International Labor Organization (2011) C189 - Domestic Workers Convention, 2011 (No. 189). Retrieved from: https://www.lo.org/dyn/normlex/en/f?p= NORMLEXPUB:12100:0::NO::P12100_ILO_CODE:C189. Accessed 7 July 2021.

International Labor Organization (2013) Promoting integration for migrant domestic workers in Europe: a synthesis of Belgium, France, Italy and Spain. Retrieved from: https://www.ilo.org/global/topics/labour-migration/publica tions/WCMS_222301/lang-en/index.htm. Accessed 7 July 2021.

International Labor Organization (2015a) Employers' perspectives towards domestic workers in Jordan: a qualitative study on attitudes, working conditions and the employment relationship. Retrieved from: https://www. 
ilo.org/beirut/publications/WCMS_429584/lang-en/index.htm. Accessed 7 July 2021.

International Labor Organization (2015b) Employers' perspectives towards domestic workers in Kuwait: a qualitative study on attitudes, working conditions and the employment relationship. Retrieved from: https://www. ilo.org/beirut/publications/WCMS_429591/lang-en/index.htm. Accessed 7 July 2021.

International Labor Organization (2016) A study of the employers of migrant domestic workers in Lebanon: Intertwined. Retrieved from: https://www.lo. org/beirut/publications/WCMS_524149/lang-en/index.htm. Accessed 7 July 2021.

International Labor Organization (2018a) Domestic workers and employers in the Arab States: promising practices and innovative models for a productive working relationship. Retrieved from: https://www.ilo.org/beirut/publications/ WCMS_619661/lang-en/index.htm. Accessed 7 July 2021.

International Labor Organization (2018b) Domestic workers and employers in the Arab States: promising practices and innovative models for a productive working relationship. Retrieved from: https://www.ilo.org/beirut/publications/ WCMS 619661/lang-en/index.htm. Accessed 7 July 2021.

International Labor Organization (2019a) Domestic workers. Retrieved from: https://www.ilo.org/global/topics/care-economy/domestic-workers/lang-en/ index.htm. Accessed 7 July 2021.

International Labor Organization (2019b) Migrant domestic workers. Retrieved from: https://www.ilo.org/global/topics/care-economy/migrant-domesticworkers/lang-en/index.htm. Accessed 7 July 2021.

Jordan Department of Statistics (2018) Estimated population of the Kingdom by governorate, locality, sex and household, 2018. Retrieved from: http:// dosweb.dos.gov.jo/ar/population/population-2/. Accessed 7 July 2021.

Jordan Ministry of Health (2006-2015) Mortality data annual reports (2006-2015). Retrieved from: http://www.moh.gov.jo/Pages/viewpage.aspx?pagelD=185. Accessed 7 July 2021.

Jordan Ministry of Labor (2009) Regulation no 90/2009 of domestic workers, cooks, gardeners and similar categories. Retrieved from: http://www.mol.gov. jo/ebv4.0/root_storage/ar/eb_list_page/\%D9\%82\%D8\%B3\%D8\%B7\%D8\%A7\% D8\%B3.pdf. Accessed 7 July 2021.

Jordan Ministry of Labor (2015) Regulation No. 12 of 2015 regulating the organization of private recruitment agencies for the recruitment of nonJordanian domestic workers. Retrieved from: https://ammanchamber.org.jo/ Uplaoded/PRNews/767.pdf. Accessed 7 July 2021.

Jordan Ministry of Labor (2016) The annual report of Jordan Ministry of Labor, Jordan. Retrieved from: http://www.mol.gov.jo/pages/viewpage.aspx?pa gelD=292. Accessed 7 July 2021.

Jordan National Center for Human Rights (2015) The 12th annual report of the National Center for Human Rights, Jordan. Retrieved from: http://www.mol. gov.jo/Pages/viewpage.aspx?pagelD=237. Accessed 7 July 2021.

Kronfol Z, Saleh M, Al-Ghafry M (2014) Mental health issues among migrant workers in Gulf Cooperation Council countries: literature review and case illustrations. Asian J Psychiatr 10:109-113. https://doi.org/10.1016/j.ajp.2014. 03.003

Manseau GS (2006) Contractual solutions for migrant labourers: the case of domestic workers in the Middle East, pp 25-47

Simkhada P, van Teijlingen E, Gurung M, Wasti SP (2018) A survey of health problems of Nepalese female migrants workers in the Middle-East and Malaysia. BMC Int Health Hum Rights 18(1):4. 45

Siriwardhana C, Wickramage K, Jayaweera K, Adikari A, Weerawarna S, van Bortel T, Siribaddana S, Sumathipala A (2015) Impact of economic labour migration: a qualitative exploration of left-behind family member perspectives in Sri Lanka. J Immigr Minor Health 17(3):885-894. https://doi.org/10.1007/s10903013-9951-0

Sonmez S, Apostolopoulos Y, Tran D, Rentrope S (2011) Human rights and health disparities for migrant workers in the UAE. Health Hum Rights 13(2):E17-E35

Tamkeen Fields for Aid (2015) Invisible women the working and living conditions of irregular migrant domestic workers in Jordan, Jordan. Retrieved from: http://tamkeen-jo.org/upload/web_Invisible_Women_English_Colored_a mended.pdf. Accessed 7 July 2021.

The Jordan Times (2015) Indonesian ban on sending workers to Jordan a blow to recruitment agencies. Retrieved from: http://www.jordantimes.com/news/ local/indonesian-ban-sending-workers-jordan-blow-recruitment-agencies\% E2\%80\%99. Accessed 7 July 2021.

United Nations Human Rights (1990) International Convention on the Protection of the Rights of All Migrant Workers and Members of Their Families, Adopted by General Assembly resolution 45/158 of 18 December 1990. Retrieved from: https://www.ohchr.org/EN/Professionallnterest/Pages/CMW.aspx. Accessed 7 July 2021.

Varia N (2011) "Sweeping changes?" A review of recent reforms on protections for migrant domestic workers in Asia and the Middle East. Can J Women Law 23(1):265-287. https://doi.org/10.3138/cjwl.23.1.265

Wickramage K, De Silva M, Peiris S (2017) Patterns of abuse amongst Sri Lankan women returning home after working as domestic maids in the Middle East: an exploratory study of medico-legal referrals. J Forensic Leg Med 45:1-6. https://doi.org/10.1016/j.jflm.2016.11.001

\section{Publisher's Note}

Springer Nature remains neutral with regard to jurisdictional claims in published maps and institutional affiliations.

\section{Submit your manuscript to a SpringerOpen ${ }^{\circ}$ journal and benefit from:}

- Convenient online submission

- Rigorous peer review

- Open access: articles freely available online

High visibility within the field

- Retaining the copyright to your article

Submit your next manuscript at $\boldsymbol{\nabla}$ springeropen.com 